COMUNICAÇÃOCIENTÍFICA

\title{
IDENTIFICAÇÃO DE MICROSSATÉLITES PARA O MAMOEIRO POR MEIO DA EXPLORAÇÃO DO BANCO DE DADOS DE DNA ${ }^{1}$
}

\author{
EDER JORGE DE OLIVEIRA ${ }^{2}$, JORGE LUIZ LOYOLADANTAS ${ }^{3}$ \\ MILENE DA SILVACASTELLEN ${ }^{4}$, MARLOS DOURADO MACHADO $^{5}$
}

RESUMO-Os marcadores microssatélites são ferramentas úteis em diversas análises genéticas em plantas. No caso do mamoeiro (Carica papaya L.), poucos locos de microssatélites foram descritos até o momento. Assim, o objetivo deste trabalho foi explorar a base de dados do GenBank / NCBI (National Center of Biotechnoloy Information) à procura de microssatélites de mamoeiro, visando a seu futuro uso em estudos genéticos e moleculares aplicados ao melhoramento genético. As sequiências foram obtidas no GenBank / NCBI, no formato FASTA, e analisadas para a presença de microssatélites com um mínimo de 20; 7 e 5 repetições dos motivos de mono-, di- e trinucleotídeos, respectivamente, e acima de 4 repetições para tetra- e pentanucleotídeos. Seqüências com mais de $90 \%$ de similaridade foram consideradas redundantes e, portanto, eliminadas das análises. Foram analisadas 44.591 seqüências, das quais 3.180 foram não-redundantes e apresentaram 3.947 microssatélites. Desse total, 3.587 foram classificados como microssatélites perfeitos, 8 imperfeitos, 65 interrompidos, 239 compostos-perfeitos, 8 compostos-imperfeitos e 40 compostos-interrompidos. As repetições de di- e trinucleotídeos representaram 65,7 e 14,4\% do total de seqüências analisadas, respectivamente. Somente os motivos do tipo AT/ TA representaram 44,1\% dos microssatélites encontrados. Os motivos mais comuns de tri-, tetra- e pentanucleotídeos foram AAT, AATT e TTTAA, respectivamente. Observou-se que, nas seqüências disponíveis, o genoma do mamoeiro apresenta, em média, um microssatélite a cada $5,65 \mathrm{~kb}$.

Termos para indexação: marcador molecular, Carica papaya L., SSR, GenBank

\section{IDENTIFICATION OF MICROSATELLITES FOR PAPAYA BY DNA DATA BANK EXPLORATION}

\begin{abstract}
Microsatellites markers are a useful tool in much plant genetic analysis. Currently, few microsatellites loci have been reported in Carica papaya L.. Therefore, the objective of this study was accomplishing a search for microsatellites in the public available - GenBank / NCBI (National Center of Biotechnology Information), aiming the future use in molecular and genetic studies applied to genetic breeding. The sequences were collected from GenBank / NCBI in FASTA-formatted files and analyzed for the presence of microsatellites with a minimum of 20, 7 and 5 repetitions of mono-, di- and trinucleotides, respectively, and above of 4 repetitions for tetra- and pentanucleotides. The sequences with over $90 \%$ of similarity, were considered redundant and, therefore, eliminated of the analyses. A total of 44,591 sequences had been analyzed, of which 3,180 were not redundant, showing 3,947 microsatellites. Out of those, 3,587 were classified as perfect, 8 imperfects, 65 interrupted, 239 perfect-compounds, 8 imperfectcompounds and 40 interrupted-compounds. The dinucleotides and trinucleotides repetitions represented 65.7 and $14.4 \%$ of the whole analyzed sequences, respectively. Only the AT/TA motif represented $44.1 \%$ of the microsatellites sequences. The most common motifs of tri-, tetra- and pentanucleotides were AAT, AATT and TTTAA, respectively. In the available sequences it can be observed that the papaya genome has an average one microsatellite for every $5,65 \mathrm{~kb}$.
\end{abstract}

Index Terms: molecular marker, Carica papaya L., SSR, GenBank.

${ }^{1}$ (Trabalho 263-07). Recebido em: 08-11-2007. Aceito para publicação em: 07-07-2008.

${ }^{2}$ Pesquisador da Embrapa Mandioca e Fruticultura Tropical, Rua da Embrapa, s/n, Caixa Postal 007, 44380-000 Cruz das Almas (BA). Endereço eletrônico: eder@cnpmf.embrapa.br

${ }^{3}$ Pesquisador da Embrapa Mandioca e Fruticultura Tropical, Rua da Embrapa, s/n, Caixa Postal 007, 44380-000 Cruz das Almas (BA). Endereço eletrônico: loyola@cnpmf.embrapa.br

${ }^{4}$ Pesquisadora da Embrapa Mandioca e Fruticultura Tropical, Rua da Embrapa, s/n, Caixa Postal 007, 44380-000 Cruz das Almas (BA). Endereço eletrônico: milene@ cnpmf.embrapa.br

${ }^{5}$ Estudante de graduação da Universidade Federal do Recôncavo da Bahia, Campus Universitário, 44380-000 Cruz das Almas (BA). Endereço eletrônico: marlosdourado@yahoo.com.br 
Os genomas eucariotos possuem muitas sequiências simples repetidas, as quais consistem de 1 a 6 nucleotídeos repetidos em tandem (Litt \& Luty, 1989). Essas regiões são denominadas de microssatélites, SSR (Simple Sequence Repeats) ou STR (Short Tandem Repeats). As seqüências de DNA que flanqueiam os microssatélites, são geralmente conservadas dentro de uma mesma espécie, permitindo o desenho de primers para amplificações específicas desses locos, via reação em cadeia da polimerase (Oliveira et al., 2006). Essas amplificações tendem a mostrar extensivo polimorfismo, que é consequiência da ocorrência de diferentes números de unidades repetidas dentro da estrutura do microssatélite (Morgante \& Olivieri, 1993). Além da capacidade de gerar altos níveis de polimorfismo, os microssatélites ainda possuem, como vantagens, a alta reprodutibilidade, a simplicidade e a rapidez da técnica, pequena quantidade de DNA requerida, baixo custo de utilização e o grande poder de resolução (Oliveira et al., 2006).

A grande limitação da tecnologia está no seu desenvolvimento, pois envolve um processo demorado, trabalhoso e com alto custo, devido à necessidade de construção de bibliotecas genômicas e screening de milhares de clones com sondas apropriadas (Kölliker et al., 2001). Recentemente, a hibridização seletiva com sondas repetitivas tem proporcionado melhores resultados no isolamento de microssatélites (Zane et al., 2002; Oliveira et al., 2005).

Apesar do avanço das pesquisas nas áreas de biologia molecular e genômica, existem poucos relatos sobre o desenvolvimento de microssatélites para o mamoeiro (Carica papaya L.). Santos et al. (2003) obtiveram 32 locos de microssatélites com o uso de bibliotecas genômicas enriquecidas. Contudo, esses microssatélites não apresentaram polimorfismo nos acessos de mamoeiro analisados. Baseado nesta mesma metodologia, Pérez et al. (2006) desenvolveram 45 microssatélites, dos quais 24 se mostraram polimórficos em acessos de $C$. papaya. Apesar disso, o número de seqüências disponíveis é insuficiente para permitir maiores avanços na conservação, uso e valoração dos recursos genéticos e, sobretudo, no melhoramento do mamoeiro, com vistas ao mapeamento genético, identificação de genes de interesse e no processo de seleção assistida.

Nos últimos anos, os projetos genoma e o surgimento de novas metodologias de seqüenciamento propiciaram a redução dos custos e o aumento expressivo do número de seqüências depositadas nos bancos de dados de DNA (GenBank / NCBI), gerando oportunidades para a identificação de microssatélites, pela estratégia de exploração desse banco (Zane et al., 2002). Assim, o objetivo do presente trabalho foi a identificação e a caracterização de microssatélites, para a cultura do mamoeiro, por meio desse screening no GenBank.

As sequiências de DNA da espécie Carica papaya L., utilizadas neste estudo, foram obtidas no GenBank / NCBI (http:/ /www.ncbi.nlm.nih.gov/), em março de 2007. As seqüências foram analisadas para a presença de microssatélites no formato FASTA. Após a obtenção das sequiências de nucleotídeos, foram feitas buscas por repetições de mono-,di-,tri-,tetra- e pentanucleotídeos, utilizando o programa Tandem Repeats Finder - TRF (Benson,
1999). Os critérios utilizados para a detecção dos microssatélites foram um mínimo de 20; 7 e 5 repetições para motivos de mono, di- e trinucleotídeos, e acima de 4 repetições para tetra- e pentanucleotídeos, respectivamente. Ao final desse processo, utilizou-se o programa Staden Package (http// staden.sourceforge.net) para verificar a existência de redundância entre as seqüências contendo os microssatélites. Sequiências com similaridade acima de $90 \%$ foram consideradas redundantes e eliminadas das análises.

Os microssatélites foram ainda classificados, de acordo com Weber (1990), com algumas modificações, em perfeitos, imperfeitos, interrompidos, composto-perfeito, compostoimperfeito e composto-interrompido.

Foram encontradas 44.591 sequiências de DNA, referentes à busca por "Carica papaya". Desse total, 45 sequiências já estavam descritas para a presença de microssatélites, de acordo com o trabalho de Pérez et al. (2006). Foram identificadas 3.760 sequiências contendo microssatélites, das quais 580 foram consideradas redundantes e retiradas das análises. Do total de 3.180 seqüências não-redundantes, observou-se a presença de 3.947 microssatélites, perfazendo um microssatélite a cada 5,65 $\mathrm{kb}$.

Foram encontrados 3.587 microssatélites perfeitos, 8 imperfeitos, 65 interrompidos, 239 compostos-perfeitos, 8 compostos-imperfeitos, e 40 compostos-interrompidos. Dentro da classe de microssatélites perfeitos, existem 130; 2.298; 659; 385 e 115 seqüências de mono-, di-, tri-, tetra- e pentanucleotídeos, respectivamente. Na classe de microssatélites imperfeitos, todas as repetições são de dinucleotídeos. No caso dos microssatélites interrompidos, existem 55 e 10 sequiências de di- e trinucleotídeos, respectivamente.

Para a classe de microssatélites compostos-perfeitos, foram encontradas $205 ; 11 ; 2 ; 6 ; 1 ; 11$ e 3 seqüências de di-, tri-, tetra-, di- + tetranucleotídeos, mono- + trinucleotídeos, tetra- + dinucleotídeos e tri- + dinucleotídeos, respectivamente. Dentro dos compostos-imperfeitos foram encontradas $4 ; 1 ; 1 ; 1$ e 1 seqüências de di-, tri-, di- + tetranucleotídeos, mono- + trinucleotídeos e tri- + dinucleotídeos, respectivamente. Já para os compostos-interrompidos, foram observadas $23 ; 6 ; 1 ; 3 ; 1 ; 1$; 1; 1 e 3 seqüências de di-, tri-, penta-, di- + tetranucleotídeos, di+ trinucleotídeos, penta- + trinucleotídeos, tetra- + dinucleotídeos, tetra- + trinucleotídeos e tri- + dinucleotídeos, respectivamente. Na Figura 1, é apresentada a distribuição das classes de repetições encontradas para os microssatélites.

Do total de microssatélites, 3,29\% são mononucleotídeos, $65,7 \%$ são repetições de dinucleotídeos, $17,41 \%$ de trinucleotídeos, 9,8\% de tetranucleotídeos, 2,94\% de pentanucleotídeos e $0,86 \%$ de outras classes (microssatélites compostos por diferentes tipos de repetições, por exemplo: (AT)n(AGA)n, que possui di- e trinucleotídeos no mesmo motivo) (Figura 1). Os motivos de mononucleotídeos mais frequientes foram (A)n e (T)n com 45,4 e 50,8\%, respectivamente. No caso dos dinucleotídicos, os motivos mais freqüentes foram (AT)n e (TA)n, que representam 40,3 e 26,8\%, respectivamente, dentre todos os dinucleotídicos identificados. Os motivos mais freqüentemente observados na classe de trinucleotídicos foram 
(AAT)n, (TTA)n e (ATT)n, correspondendo a 14,3; 11,35 e 8,0\% de todos os trinucleotídicos. Na classe de tetranucleotídeos, os motivos (AATT)n, (TTTA)n, (AAAT)n e (TTAA)n representam 25,$6 ; 8,3 ; 7,5$ e 7,0\%, respectivamente, desse tipo de repetição. Enquanto para os pentanucleotídeos, os motivos (TTTAA)n, (TTTTA)n, (TAAAA)n e (ATTTA)n, correspondem a 12,9; 8,6; 6,9 e $6,0 \%$, respectivamente, desse tipo de seqüência.

Em geral, todos os tamanhos de motivos apresentaram um mesmo padrão com relação ao número total de regiões microssatélites identificadas e ao número de repetições, mostrando que locos microssatélites com maior número de repetições são mais raros. O tamanho dos microssatélites foi, aqui definido, em função do número de repetições nãointerrompidas. Assim, as seqüências de mononucleotídeos apresentaram, em média, 23,1 $\pm 3,4$ (desvio-padrão) repetições, as de di- 10,6 $6 \pm 4,0$; as de tri- $6,3 \pm 2,0$; as de tetra- $4,4 \pm 0,9$; as de penta- 4,3 $\pm 0,6$ e as outras classes apresentaram, em média, $15,2 \pm 5,4$ repetições. O maior número de repetições foi encontrada para o dinucleotídeo interrompido do tipo (AG)30aa(AG)13.

De acordo com Zane et al. (2002), o desenvolvimento de microssatélites pela estratégia de exploração de dados no GenBank pode reduzir o tempo e os custos de sua obtenção, tendo em vista que a criação de grandes programas de seqüenciamento do genoma (como um todo ou de suas partes) oferece um grande número de seqüências disponíveis para tal finalidade. No caso do mamoeiro, foram identificados 3.180 sequiências contendo 3.947 microssatélites, das quais é possível desenhar pares de primers para 2.814 microssatélites distribuídos em 2.408 seqüências.

Com relação à eficiência em termos de sequiências analisadas $v s$. microssatélites obtidos, o presente trabalho obteve $8,8 \%$ de eficiência, que pode ser considerada alta, mediante observações de outros autores, como Kantety et al. (2002), que analisaram cerca de 260.000 seqüências de ESTs de cinco diferentes espécies de cereais, e encontraram frequiências que variaram de $1,5 \%$ a $4,7 \%$ em milho e arroz, respectivamente. No caso específico do mamoeiro, Santos et al. (2003) utilizaram a abordagem convencional que envolve a construção de bibliotecas genômicas enriquecidas com sondas do tipo (TCA)10, e obtiveram uma eficiência de enriquecimento de apenas $2,1 \%$.

De acordo com os resultados obtidos, os dinucleotídeos representam $65,7 \%$ dos microssatélites no mamoeiro. As repetições de dinucleotídeos mais encontradas no genoma de plantas são AT/TA, AG/TC, seguidas de AC/GT; e as de trinucleotídeos são TAT e TCT (Morgante \& Olivieri, 1993). No caso dos dinucleotídeos, os dados obtidos no presente trabalho corroboram as observações desses autores, uma vez que os motivos AT/TA e GA/TC + AG/CT foram os mais freqüentes. Já para os trinucleotídeos, as repetições AAT e TTA foram as mais freqüentes, representando 14,3 e 11,4\% do total de seqüências disponíveis nessa classe, enquanto as repetições do tipo TAT e TCT representam apenas 4,8 e $4,4 \%$.

Independentemente da classificação, os resultados obtidos demonstram que a distribuição dos microssatélites no genoma do mamoeiro é de 1 loco a cada 5,65 kb. Esses dados estão próximos daqueles observados para outras espécies, como, por exemplo, um loco a cada 3,4 kb em arroz, 8,1 kb em milho, 7,4 kb em soja, $11,1 \mathrm{~kb}$ em tomate e $20 \mathrm{~kb}$ em algodão (Cardle et al., 2000).

O desenvolvimento de ferramentas moleculares baseadas em marcadores microssatélites poderá contribuir sobremaneira para elucidar o controle genético de algumas características quantitativas complexas, além de permitir a construção de mapas genéticos, a identificação de regiões cromossômicas associadas a QTLs (Quantitative Trait Loci), bem como seus efeitos sobre o caráter em estudo. Dessa forma, o uso de marcadores microssatélites, associados aos métodos tradicionais de melhoramento permitirão o estabelecimento da seleção assistida por marcadores (SAM) para melhorar a dinâmica e a eficiência dos programas de melhoramento, de forma a superar as limitações da seleção fenotípica supracitada.

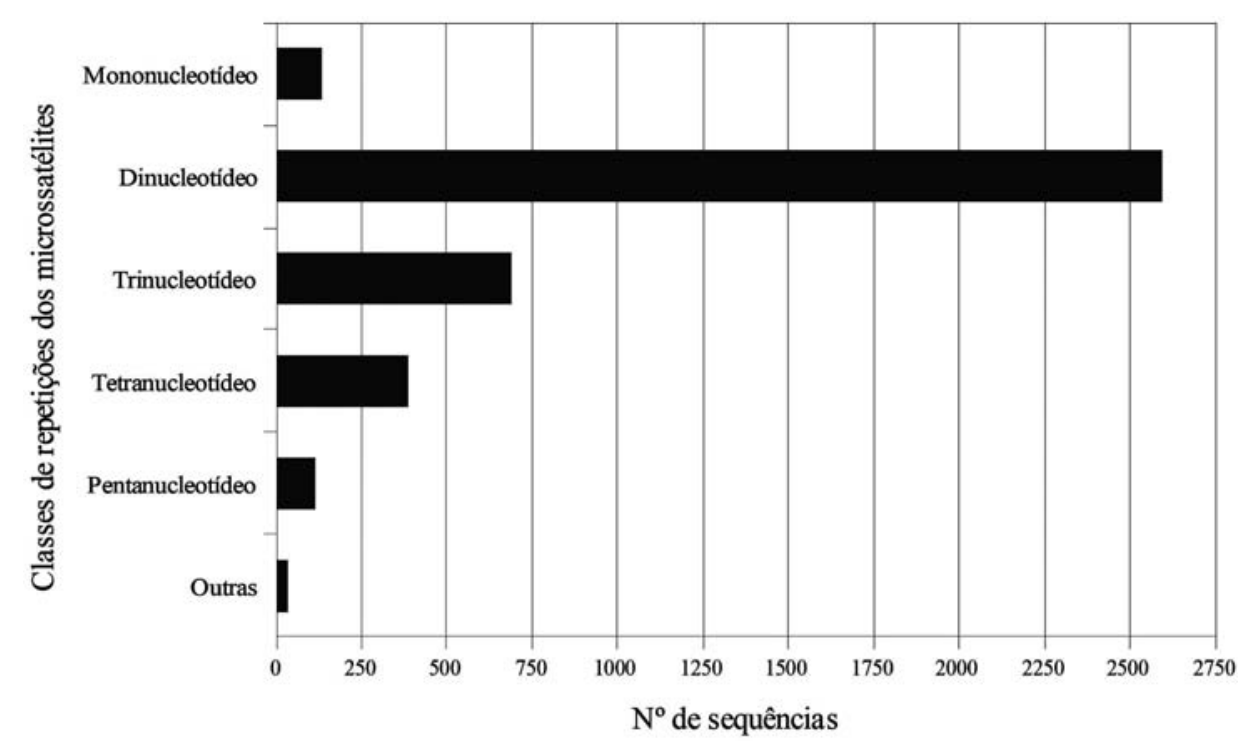

FIGURA 1 - Distribuição das classes de microssatélites encontradas para o mamoeiro no GenBank. 


\section{REFERÊNCIAS}

ASHKENAZI, V.; CHANI, E.; LAVI, U.; LEVY, D. HILLEL, J.; VEILLEUX, E. Development of microsatellite markers in potato and their use in phylogenetic and fingerprinting analyses. Genome, Ottawa, v.44, n.1, p.50-62, 2001.

BENSON, G. Tandem repeats finder: a program to analyze DNA sequences. Nucleic Acids Research, London, v.27, n.2, p.573580,1999 .

BENSON, G. Tandem repeats finder: a program to analyze DNA sequences. Nucleic Acids Research, London, v.27, n.2, p.573580,1999 .

BRONDANI, R. P. V.; BRONDANI, C.; TARCHINI, R.; GRATTAPAGLIA, D. 1998. Development, characterization and mapping of microssatellite markers in Eucalyptus grandis and $E$. urophylla. Theoretical and Applied Genetics, Berlin, v.97, n.5-6, p.816-827.

CARDLE, L.; RAMSAY,L.; MILBOURNE, D.; MACAULAY, M.; MARSHALL, D.; WAUGH, R. Computational and experimental characterization of physically clustered simple sequence repeats in plants. Genetics, Baltimore, v.156, n.2, p. 847-857, 2000.

GUPTA, P.K.; RUSTGI, S.; SHARMA, S.; SINGH, R.; KUMAR, N.; BALYAN, H.S. Transferable EST-SSR markers for the study of polymorphism and genetic diversity in bread wheat. Molecular Genetics and Genomics, Berlin, v. 270, n.4, p. 315-323, 2003.

HAMWIEH, A.; UDUPA, S.M.; CHOUMANE, W.; SARKER, A.; DREYER, F.; JUNG, C.; BAUM, M. A genetic linkage map of Lens sp. based on microsatellite and AFLP markers and the localization of fusarium vascular wilt resistance. Theoretical and Applied Genetics, Berlin, v.110, n.4, p.669-677, 2005.

KANTETY, R.V.; LA ROTA, M.; MATTHEWS, D.E.; SORRELL, M.E. Data mining for simple sequence repeats in expressed sequence tags from barley, maize, rice, sorghum and wheat. Plant Molecular Biology, Dordrecht, v. 48, n.5-6, p. 501-510, 2002.

KIJAS, J.M.; FOWLER, J.C.; GARBETT, C.A.; THOMAS, M.R. Enrichment of microsatellites from the citrus genome using biotinylated oligonucleotide sequences bound to streptavidincoated magnetic particles. Biotechniques, London, v.16, n.4, p.656-662, 1994

KÖLLIKER, R.; JONES, E.S.; DRAYTON, M.C.; DUPAL, M.P.; FOSTER, J.W. Development and characterisation of simple sequence repeat (SSR) markers for white clover (Trifolium repens L.). Theoretical and Applied Genetics, Berlin, v.102, n.2-3, p.416$424,2001$.

LITT, M.; LUTY, L.A. A hypervariable microsatellite revealed by in vitro amplification of a dinucleotide repeat within the cardiac muscle actin gene. American Journal of Human Genetics, Chicago, v.44, n.3, p.398-401, 1989.

MAHALAKSHMI, V.; APARNA, P.; RAMADEVI, S.; ORTIZ, R. 2002. Genomic sequence derived simple sequence repeats markers: a case study with Medicago spp. Electronic Journal of Biotechnology, Valparaiso, v.5, n.3, p.233-242.

MASON, S.L.; STEVENS, M.R.; JELLEN, E.N.; BONIFACIO, A.; FAIRBANKS, D.J.; COLEMAN, C.E.; MCCARTY, R.R.; RASMUSSEN, A.G.; MAUGHAN, P.J. Development and use of microsatellite markers for germplasm characterization in Quinoa (Chenopodium quinoa Willd.). Crop Science, Madison, v. 45, n.4,p.1618-1630, 2005.

McCOUCH, R.; TEYTELMAN, L.; XU, Y.; LOBOS, K.B.; CLARE, K.; WALTON, M.; FU, B.; MAGHIRANG, R.; LI, Z.; XING, Y.; ZHANG, Q.; KONO, I.; YANO, M.; FJELLSTROM, R.; DECLERCK, G.; SCHNEIDER, D.; CARTINHOUR, S.; WARE, D.; STEIN, L. Development and mapping of 2240 new SSR markers for rice (Oryza sativa L.). DNA Research, Oxford, v.9, n.6, p.199207, 2002.

MORGANTE, M.; OLIVIERI, A. M. PCR-amplified microsatellites as markers in plant genetics. The Plant Journal, Gainesville, v.3, n.1, p.175-182, 1993.

OLIVEIRA, E. J.; PÁDUA, J. G.; ZUCCHI, M. I.; VENCOVSKY, R.; VIEIRA, M. L. C. 2006. Origin, evolution and genome distribution of microsatellites. Genetics and Molecular Biology, Ribeirão Preto, v.29, n.2, p.294-307, 2006.

OLIVEIRA, E.J. Desenvolvimento e uso de marcadores microssatélites para construção e integração de mapas genéticos de maracujá-amarelo (Passiflora edulis Sims f. flavicarpa Deg.). 2006. 152 f. Tese (Doutorado) - Escola Superior de Agricultura “Luiz de Queiroz”, Piracicaba, Universidade de São Paulo, 2006.

OLIVEIRA, E.J.; PÁDUA, J.G.; ZUCCHI, M.I.; CAMARGO, L.E.A.; FUNGARO, M.H.P.; VIEIRA, M.L.C. Development and characterization of microsatellite markers from the yellow passion fruit (Passiflora edulis f. flavicarpa). Molecular Ecology Notes, Oxford, v.5, n.2, p.331-333, 2005.

PÉREZ， J. O.; DAMBIER， D.; OLlITRAULT, P.; D'EECKENBRUGGE, G. C.; BROTTIER, P.; FROELICHER, Y.; RISTERUCCI, A. M. 2006. Microsatellite markers in Carica papaya L.: isolation, characterization and transferability to Vasconcellea Species. Molecular Ecology Notes, Oxford, v.6, n.1, p.212-217.

PRIOLLI, R.H.G.; MENDES-JUNIOR, C.T.; ARANTES, N.E.; CONTEL, E.P.B. Characterization of Brazilian soybean cultivars using microsatellite markers. Genetics and Molecular Biology, Ribeirão Preto, v.25, n.2, p.185-193, 2002. 
RASSMANN, K.; SCHLÖTTERER, C.; TAUTZ, D. Isolation of simple sequence loci for use in polymerase chain reaction-based DNA fingerprinting. Electrophoresis, Weinheim, v.12, n.2-3, p.113$118,1991$.

SANTOS, S. C.; RUGGIERO, C.; SILVA, C. L. S. P.; LEMOS, E. G. M. 2003. A microsatellite library for Carica papaya L. cv. Sunrise Solo. Revista Brasileira de Fruticultura, Jaboticabal, v.25, n.2, p.263-267.

SCHLÖTTERER, C. Evolutionary dynamics of microsatellite DNA. Chromosoma, Berlin, v.109, n.6, p.365-371, 2000.

SCHLÖTTERER, C.; TAUTZ, D. Slippage synthesis of simple sequence DNA. Nucleic Acids Research, Oxford, v. 20, n.2, p. 211-215, 1992

STRAND, M.; PROLLA, T.A.; LISKAY, R.M.; PETES, T.D. Destabilization of tracts of simple repetitive DNA in yeast by mutations affecting DNA mismatch repair. Nature, London, v.365, p.274-276, 1993.
WANCHANA, S.; KAMOLSUKYUNYONG, W.; RUENGPHAYAK, S.; TOOJINDA, T.; TRAGOONRUNG, S.; VANAVICHIT, A. A rapid construction of a physical contig across a $4.5 \mathrm{cM}$ region for rice grain aroma facilitates marker enrichment for positional cloning. Scientia Asia, Bangkok, v. 31, n.3, p. 299306, 2005.

WEBER, J. L. Informativeness of human (dC-dA)n (dG-dT)n polymorphisms. Genomics, San Diego, v.7, n.4, p.524-530, 1990.

WRIGHT, J.M.; BENTZEN, P. Microsatellites, genetic markers of the future. Reviews in Fish Biology and Fisheries, London, v.4, n.3, p.384-388, 1994.

ZANE, L.; BARGELLONI, L.; PATARNELLO, T. Strategies for microsatellite isolation: a review. Molecular Ecology, Oxford, v.11, n.1, p.1-16, 2002.

ZUCCHI, M.I.; BRONDANI, R.V.; PINHEIRO, J.B.; BRONDANI, C.; VENCOVSKY, R. Transferability of microsatellite markers from Eucalyptus spp. to Eugenia dysenterica (Myrtaceae family). Molecular Ecology Notes, Oxford, v.2, n.4, p.512-514, 2002. 